\title{
A novel mitochondrial ATP8 gene mutation in a patient with apical hypertrophic cardiomyopathy and neuropathy
}

\author{
A I Jonckheere, ${ }^{1}$ M Hogeveen, ${ }^{1}$ L G J Nijtmans, ${ }^{1}$ M A M van den Brand, ${ }^{1}$ \\ A J M Janssen, ${ }^{1} \mathrm{~J}$ H S Diepstra, ${ }^{1} \mathrm{FC}$ A van den Brandt, ${ }^{1} \mathrm{~L}$ P van den Heuvel, ${ }^{1} \mathrm{~F}$ A Hol, ${ }^{2}$ \\ T G J Hofste, ${ }^{2}$ L Kapusta, ${ }^{1}$ U Dillmann, ${ }^{3}$ M G Shamdeen, ${ }^{3}$ J A M Smeitink, \\ R J T Rodenburg ${ }^{1}$
}

\begin{abstract}
${ }^{1}$ Department of Pediatrics at the Nijmegen Centre for

Mitochondrial Disorders,

Radboud University Nijmegen

Medical Centre, Nijmegen, The

Netherlands; ${ }^{2}$ Human Genetics at the Nijmegen Centre for Mitochondrial Disorders, Radboud University Nijmegen Medical Centre, Nijmegen, The Netherlands; ${ }^{3}$ Departments of Neurology and Pediatric and Juvenile Medicine, Saarland University, Homburg, Saar, Germany
\end{abstract}

Correspondence to: Professor J A M Smeitink Nijmegen Centre for Mitochondrial Disorders, Geert Grooteplein 10, P0 Box 9101. 6500 HB Nijmegen, The Netherlands; j.smeitink@cukz. umcn.nl

Received 18 September 2007 Revised 9 October 2007 Accepted 10 October 2007 Published Online First 22 October 2007

\section{ABSTRACT}

Purpose: To identify the biochemical and molecular genetic defect in a 16-year-old patient presenting with apical hypertrophic cardiomyopathy and neuropathy suspected for a mitochondrial disorder.

Methods: Measurement of the mitochondrial energygenerating system (MEGS) capacity in muscle and enzyme analysis in muscle and fibroblasts were performed. Relevant parts of the mitochondrial DNA were analysed by sequencing. Transmitochondrial cybrids were obtained by fusion of 143B206 $\mathrm{TK}^{-}$rho zero cells with patient-derived enucleated fibroblasts. Immunoblotting techniques were applied to study the complex $\mathrm{V}$ assembly.

Results: A homoplasmic nonsense mutation $\mathrm{m} .8529 \mathrm{G} \rightarrow \mathrm{A}(\mathrm{p}$.Trp55X) was found in the mitochondrial ATP8 gene in the patient's fibroblasts and muscle tissue. Reduced complex $\mathrm{V}$ activity was measured in the patient's fibroblasts and muscle tissue, and was confirmed in cybrid clones containing patient-derived mitochondrial DNA. Immunoblotting after blue native polyacrylamide gel electrophoresis showed a lack of holocomplex $\mathrm{V}$ and increased amounts of mitochondrial ATP synthase subcomplexes. An in-gel activity assay of ATP hydrolysis showed activity of free $F_{1}$-ATPase in the patient's muscle tissue and in the cybrid clones.

Conclusion: We describe the first pathogenic mutation in the mitochondrial ATP8 gene, resulting in an improper assembly and reduced activity of the complex $\mathrm{V}$ holoenzyme.

Mitochondrial (mt) ATP synthase, or complex V (EC 3.6.3.14), uses the proton gradient provided by the activity of the respiratory chain enzymes complexes I, III and IV for ATP synthesis, thereby generating $>95 \%$ of cellular ATP. ${ }^{1}$ Complex V is a multisubunit complex consisting of two functional domains, $\mathrm{F}_{1}$ and $\mathrm{F}_{0}$, connected by a stalk. The $\mathrm{F}_{1}$ domain contains five different subunits (three $\alpha$, three $\beta$, and one $\gamma \delta \varepsilon$ ), is situated in the mitochondrial matrix and acts as the catalytic domain. The $\mathrm{F}_{0}$ domain is embedded in the mitochondrial inner membrane and consists of eight subunits ( $\mathrm{a}-\mathrm{g}$ and A6L). The stalk contains the subunits OSCP, F6, b and $\mathrm{d}^{2}$ Protons pass from the intermembrane space to the matrix through $\mathrm{F}_{0}$, which transfers the energy created by the proton electrochemical gradient to $F_{1}$, where $\mathrm{ADP}$ is phosphorylated to ATP. ${ }^{23}$ It has been proposed that a shaft ("rotor" consisting of the ring of $10 \mathrm{c}$ subunits, plus the subunits $\gamma, \delta$ and $\varepsilon$ that form the central stalk) linked to $F_{0}$ rotates relative to the catalytic subunits (three $\alpha$, three $\beta$ ) of $F_{1}$, thereby sequentially changing the conformation of these subunits, creating the "binding change mechanism of energy coupling" proposed by Boyer. ${ }^{4-6}$ Two of the $\mathrm{F}_{0}$ subunits, subunit a (or subunit 6) and subunit A6L (or subunit 8) are encoded by the mtDNA ATP6 and ATP8 genes, respectively. ${ }^{7}$ To date, mtDNA complex $\mathrm{V}$ mutations have only been described in the mitochondrial ATP6 gene (MT-ATP6). The point mutations $\mathrm{m} .8993 \mathrm{~T} \rightarrow \mathrm{G} / \mathrm{C}$ are the most commonly encountered MT-ATP6 mutations and, depending on the degree of heteroplasmy, mainly lead to the clinical picture of NARP (neuropathy, ataxia, and retinitis pigmentosa) or to the more severe MILS (maternally inherited Leigh syndrome). ${ }^{18}$ ATP synthase deficiency due to nuclear genetic defects has also been described. ${ }^{19}$ To our knowledge, pathogenic mutations in the mitochondrial ATP8 gene have not been published to date. ${ }^{10}$ We describe a 16 -year-old patient presenting with apical hypertrophic cardiomyopathy and neuropathy. Biochemical analysis performed in muscle tissue and fibroblasts showed an isolated complex $\mathrm{V}$ deficiency. Mutation analysis of mtDNA revealed a pathogenic nonsense mutation in MT-ATP8. We studied the molecular pathophysiology of this novel mtDNA mutation using transmitochondrial cybrid cells.

\section{CASE REPORT}

The patient is the third child of healthy, nonconsanguineous Caucasian parents. His older brother and sister are healthy. The family history is unremarkable. According to the parents, his speech development was delayed but turned to normal after an adenotomy at the age of 4 years. He has worn glasses since the age of 3 years for hypermetropia and astigmatism, and one eye was temporarily covered because of amblyopia. His motor development has been slower than his siblings since infancy. He walked independently at the age of 18-24 months, and learned to ride a bicycle at the age of 7-8 years. During childhood, he had frequent falls, and his gross motor skills were clumsy. At the age of 9-10 years, his balance problems became prominent. Since then there have been reports of reduced muscle strength, walking 
problems and tingling in the limbs. These symptoms appear to be progressive. Exercise intolerance, shortness of breath (dyspnoea) during exercise, and angina were also common symptoms.

Clinical examination at the age of 16 years showed a slender young man, whose speech was dysarthric. He had an ataxic walking pattern and revealed a clear Trendelenburg sign. Reduced tendon reflexes and a bilateral Babinski sign were present. Moderate external ophthalmoplegia was noted. Metabolic tests performed at the age of 14 years showed normal blood lactic acid concentrations, with increased lactic acid in the cerebrospinal fluid $(4000 \mu \mathrm{mol} / \mathrm{l}$; normal range 1350 to 1900). The organic acid pattern in the urine was normal. Ophthalmological evaluation confirmed the astigmatism and hypermetropia, and showed no signs of retinitis pigmentosa. Audiology was normal. MRI of the brain did not show any abnormalities other than a cisterna magna. Neuropsychological evaluation revealed a moderate learning disorder. Cardiac evaluation showed an extensive left ventricular hypertrophy on the ECG, without signs of arrhythmia. Echocardiography was abnormal: left ventricular hypertrophy was concentrated around the apex of the left ventricle (fig 1) with discrete asymmetrical hypertrophy of the echogenic interventricular septum and without left ventricular outflow tract obstruction. A small atrial septal defect with left to right shunt was detected. At this age, sensory and motor axonal polyneuropathy was seen on an electromyogram; the sensory potentials could not be evoked in the sural nerve bilaterally, and there were slightly delayed motor nerve conduction velocities with reduced amplitudes in the peroneal and tibial nerves. Finally muscle (quadriceps femoris) and skin biopsies were taken.

\section{METHODS}

\section{Cell cultures}

Fibroblasts were cultured in M199 medium (Gibco, Invitrogen, Breda, The Netherlands) supplemented with 10\% fetal calf serum and penicillin/streptomycin (respectively $100 \mathrm{U} / \mathrm{ml}$ and $100 \mu \mathrm{g} / \mathrm{ml}$ ). Transmitochondrial cybrids were obtained by fusion of 143B206 $\mathrm{TK}^{-}$rho zero cells with enucleated fibroblasts derived from patient or control as described previously. ${ }^{11}$ Seven independent colonies (clones) of the patient transmitochondrial cybrid cell line were randomly picked for further study. For the

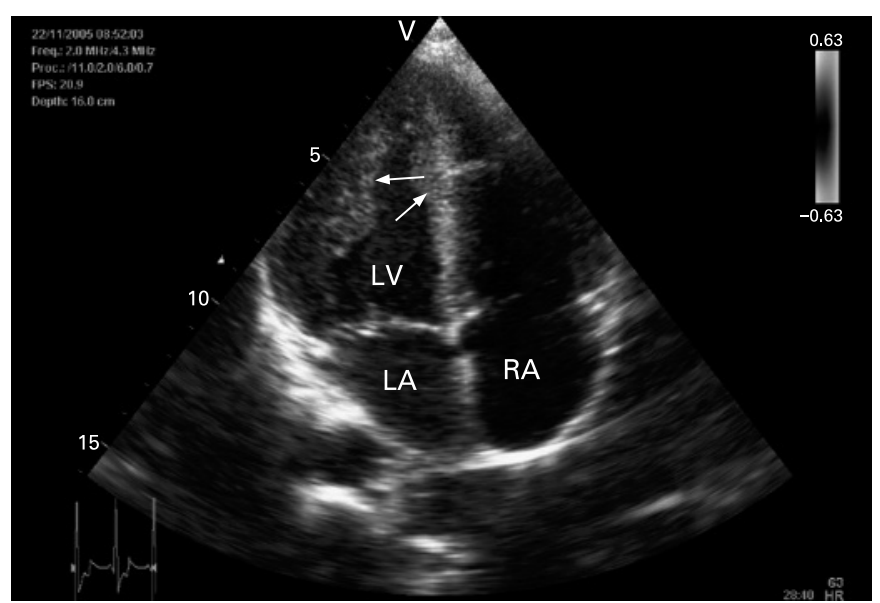

Figure 1 Echocardiography showing apical left ventricular hypertrophy. $L A$, left atrium; $R A$, right atrium; $L V$, left ventricle; $R V$, right ventricle; arrows, myocardial hypertrophy. control cybrid cell line, the colonies were pooled, resulting in a clone mixture.

\section{Biochemical assays}

Measurement of MEGS capacity was performed as described previously. ${ }^{12}$ The complex $\mathrm{V}$ (or mtATPase) activity was measured spectrophotometrically in mitochondria isolated from frozen pellets of the patient and control cybrids as described previously. ${ }^{8}$ Briefly a $980 \mu \mathrm{l}$ solution containing $250 \mathrm{mmol} / \mathrm{l}$ sucrose, $50 \mathrm{mmol} / \mathrm{l} \mathrm{KCl}, 50 \mathrm{mmol} / \mathrm{l} \quad \mathrm{K}_{2} \mathrm{HPO}_{4}, 50 \mathrm{mmol} / \mathrm{l}$ $\mathrm{KH}_{2} \mathrm{PO}_{4}, 1 \mathrm{mmol} / 1$ phosphoenolpyruvic acid, $11 \mathrm{nmol} / 1 \mathrm{P}^{1}-\mathrm{P}^{5}-$ di(adenosine-5') pentaphosphate, $0.2 \mathrm{mmol} / 1 \mathrm{EGTA}, 5 \mathrm{mmol} / \mathrm{l}$ ATP, $5 \mathrm{mmol} / 1 \mathrm{MgCl}_{2}, 0.2 \mathrm{mmol} / \mathrm{l}$ oubaine, $2 \mu \mathrm{mol} / 1$ carbonyl cyanide 3-chlorophenyl hydrazone (CCCP), $250 \mu \mathrm{mol} / \mathrm{l} \mathrm{NADH}$, $1.25 \mu \mathrm{mol} / \mathrm{l}$ rotenone, $2.5 \mathrm{U} / \mathrm{ml}$ lactate dehydrogenase, and $1.5 \mathrm{U} / \mathrm{ml}$ pyruvate kinase was incubated for 10 minutes at $30^{\circ} \mathrm{C}$. A mitochondrial suspension was freeze-thawed three times and $20 \mu \mathrm{l}$ was added to the reaction mixture, mixed and transferred to a cuvette, after which the absorption at $340 \mathrm{~nm}$ was measured for 8 minutes. Subsequently, $1 \mu \mathrm{l}$ of an $8 \mathrm{mg} / \mathrm{ml}$ oligomycin solution in ethanol was added and the absorption was measured for another 8 minutes. The oligomycin-sensitive activity of complex $\mathrm{V}$ was calculated using an $\varepsilon_{340}$ for $\mathrm{NADH}$ of $6.22 \times 10^{3} \mathrm{l} / \mathrm{mol} \times \mathrm{cm}$ and was expressed in units (the amount of enzyme required to convert $1 \mu \mathrm{mol} \mathrm{NADH} / \mathrm{min}$ ) per unit cytochrome oxidase $(\mathrm{COX})^{13}$ and the mitochondrial matrix enzyme citrate synthase $(\mathrm{CS})^{14}$ activities, respectively. The activities of the mitochondrial respiratory chain enzymes were measured spectrophotometrically in muscle tissue and fibroblasts of our patient according to described protocols. ${ }^{15} 16$

\section{Molecular genetic analysis}

Total DNA from frozen skeletal muscle tissue and from cultured fibroblasts was extracted using the Gentra genomic isolation kit according the protocol of the manufacturer (Biozym, Landgraaf, The Netherlands). Major DNA deletions or other rearrangements in the mtDNA were screened for using standard long-template PCR. The presence of the MELAS m.3243A $\rightarrow$ G, MERFF $\mathrm{m} .8344 \mathrm{~A} \rightarrow \mathrm{G}$ and Leigh/NARP $\mathrm{m} .8993 \mathrm{~T} \rightarrow$ G/C point mutations was investigated using Pyrosequencing technology as described previously. ${ }^{817}$ Sequence analysis of PCR amplified products of the mtDNA-encoded tRNA ${ }^{\mathrm{Gln}}$, tRNA ${ }^{\mathrm{Gly}}$,

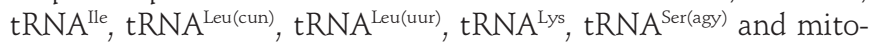
chondrial ATP6 and ATP8 genes was performed on an ABI3730 automatic capillary sequencer using BigDye terminator chemistry (Applied Biosystems, Nieuwerkerk a/d ljssel, The Netherlands). Primers used for amplification of tRNA genes are available upon request. $M T-A T P 6$ and $M T-A T P 8$ were amplified by PCR as three overlapping fragments $(\mathrm{a}, \mathrm{b}$ and $\mathrm{c})$ using the primers shown in table 1. PCR conditions were $92^{\circ} \mathrm{C}$ for 30 seconds, $55^{\circ} \mathrm{C}$ for 30 seconds and $72^{\circ} \mathrm{C}$ for 60 seconds, for 35 cycles. Subsequently, mtDNA was analysed in the patient and control cybrids looking for the nonsense mutation $\mathrm{m} .8529 \mathrm{G} \rightarrow \mathrm{A}$ following the protocol described above.

Table 1 Primers used for amplification of MT-ATP6 and MT-ATP8

\begin{tabular}{lll}
\hline & Primer $\mathbf{5}^{\prime} \rightarrow \mathbf{3}^{\prime}$ & \\
\cline { 2 - 3 } & Forward & Reverse \\
\hline a & cggtcaatgctctgaaatctgtg & gagatatttggaggtggggatc \\
b & ctgttcgcttcattcattgcc & gtggcgcttccaattaggtg \\
c & cccacttcttaccacaaggc & gtgctttctcgtgttacatcg \\
\hline
\end{tabular}




\section{Complex V assembly and activity}

Blue native polyacrylamide gel electrophoresis (BN-PAGE), blotting and measurement of complex $\mathrm{V}$ in-gel activity was performed as described previously, ${ }^{18}{ }^{19}$ loading $60 \mu$ g of protein ${ }^{20}$ of oxidative phosphorylation complexes isolated from a mitoplast fraction of the patient and control cybrids and muscle homogenates. For Western blotting, monoclonal antibodies against mitochondrial ATP synthase subunit $\alpha$ and CoII-70 kDa (complex II) (Invitrogen, Breda, The Netherlands) were used. For the complex $\mathrm{V}$ in-gel activity assay the gel was incubated overnight at room temperature with the following solution: $35 \mathrm{mmol} / \mathrm{l}$ Tris, $270 \mathrm{mmol} / \mathrm{l}$ glycine, $14 \mathrm{mmol} / \mathrm{l} \mathrm{MgSO}_{4}, 0.2 \%$ $\mathrm{Pb}\left(\mathrm{NO}_{3}\right)_{2}$, and $8 \mathrm{mmol} / \mathrm{l} \mathrm{ATP}, \mathrm{pH}$ 7.8. ${ }^{19}$

\section{RESULTS}

\section{Biochemical assays}

Measurement of MEGS capacity in muscle tissue showed a reduced pyruvate oxidation rate, which improved after addition of CCCP, pointing to a possible complex $\mathrm{V}$ defect. ${ }^{12}$ The ATP production rate from oxidation of pyruvate was reduced. Spectrophotometric analysis confirmed the reduced complex V (mtATPase) activity in muscle tissue and in fibroblasts. The activities of the respiratory chain enzymes and CS were normal (table 2).

\section{Molecular genetic analysis}

The diagnosis of a mitochondriopathy was further substantiated by mutation analysis of mtDNA from muscle tissue and fibroblasts, showing a homoplasmic $(\rightarrow 90 \%)$ nonsense mutation $\mathrm{m} .8529 \mathrm{G} \rightarrow \mathrm{A}(\mathrm{p} . \operatorname{Trp} 55 \mathrm{X})$ in the mitochondrial ATP8 gene, located in an overlap region of MT-ATP6 and MT-ATP8 (nucleotides m.8527-8572). It results in a silent change in $M T$ ATP6 (Met1Met; ATG $\rightarrow$ ATA), whereas it introduces a premature stop codon in the C-terminal domain of MT-ATP8, which is a conserved region ${ }^{10}{ }^{21}$ (fig 2). This probably results in a truncated protein lacking the last 14 amino acids.

\section{Cell biological consequences}

DNA analysis in the cybrid cells confirmed the presence of the mitochondrial nonsense mutation $\mathrm{m} .8529 \mathrm{G} \rightarrow \mathrm{A}$ in each of the clones containing patient-derived mtDNA. Sequence analysis showed that all clones were homoplasmic for the mutation. The control cybrid cell line showed no mutation (fig 3).

Table 2 Measurement of MEGS capacity in muscle tissue and enzymatic analysis of the activities of complex V (mtATPase), the respiratory chain enzymes and CS in muscle tissue and fibroblasts

\begin{tabular}{lll}
\hline & Muscle tissue & Fibroblasts \\
\hline$\left[1-{ }^{14} \mathrm{C}\right]$ Pyruvate + malate* & 2.25 & $\mathrm{ND}$ \\
{$\left[1-{ }^{14} \mathrm{C}\right]$ Pyruvate + malate-ADP + CCCP† } & 4.39 & $\mathrm{ND}$ \\
ATP production rate: & 22 & $\mathrm{ND}$ \\
Complex V, mU/U COX & $54(169$ to 482$)$ & $122(209$ to 935$)$ \\
Complex I, mU/U CS & $73(70$ to 251$)$ & $223(110$ to 260$)$ \\
Complex II, mU/U CS & $518(335$ to 749$)$ & $812(536$ to 1027$)$ \\
Complex III, mU/U CS & $3438(2200$ to 6610$)$ & $1998(1270$ to 2620$)$ \\
Complex IV, mU/U CS & $2134(810$ to 3120$)$ & $797(680$ to 1190$)$ \\
CS, mU/mg & $231(37.4$ to 162$)$ & $398(144$ to 257$)$ \\
\hline
\end{tabular}

CCCP, carbonyl cyanide 3-chlorophenyl hydrazone; COX, cytochrome oxidase; CS, cytrate synthase; MEGS, mitochondrial energy-generating system; ND, not determined.

Figures in brackets are normal ranges.

${ }^{*}$ Expressed as $\mathrm{nmol}{ }^{14} \mathrm{CO}_{2} / \mathrm{hxmU} \mathrm{CS}$; normal 3.45-7.99.

†Expressed as $\mathrm{nmol}{ }^{14} \mathrm{CO}_{2}$ /hxmU CS; normal 3.45-7.99.

Expressed as nmol (ATP+CrP)/h $\times \mathrm{mU}$ CS; normal 36-81.7.

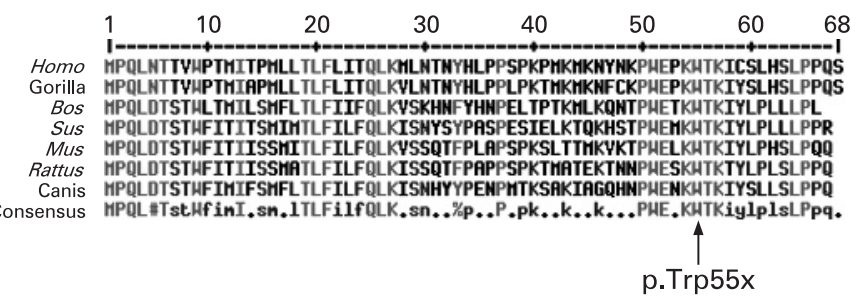

Figure 2 The C-terminal domain of mitochondrial ATP synthase subunit 8 is a conserved region in mammals. p.Trp55X, mutation site at the protein level.

Enzymatic analysis of complex $\mathrm{V}$ was performed in the patient cybrid clones and in the control cybrid clone mixture. A distinctly reduced activity was found in the patient cell line relative to the control (table 3 ). CS and COX activities were normal in the patient and control cybrids (data not shown).

A larger range of residual activities in individual cybrids is seen when normalised to the COX activity because the COX assay has a broader normal range than the CS assay.

Immunoblotting after blue native polyacrylamide gel electrophoresis (fig 4) with anti-ATP synthase subunit $\alpha$ antibody clearly revealed a lack of holocomplex $\mathrm{V}$ and increased amounts of subcomplexes of mitochondrial ATP synthase in the patient cybrid clones and muscle homogenate. This was not found in the control cybrid and control muscle, which showed only the complex $\mathrm{V}$ holoenzyme and dimer. The most likely subcomplexes are the $\mathrm{F}_{1}$-ATPase and the subcomplex $\mathrm{V}^{*}$, as denoted previously. ${ }^{22}$ The in-gel activity assay of ATP hydrolysis showed activity of free $\mathrm{F}_{1}$-ATPase in the patient cybrid clones and muscle. The holoenzyme showed no activity in either the patient or control samples (fig 5).

\section{DISCUSSION \\ Clinical phenotype}

We describe the first pathogenic mutation in the mitochondrial ATP8 gene, to our knowledge. It has been stated previously that the clinical phenotype of complex $\mathrm{V}$ deficiency due to nuclear genetic defects (hypertrophic cardiomyopathy, hypotonia, facial dysmorphism and microcephaly) markedly differs from the severe central system changes observed in NARP or MILS. ${ }^{1}$ The clinical phenotype of our patient is characterised by signs and symptoms that have mainly been described both in

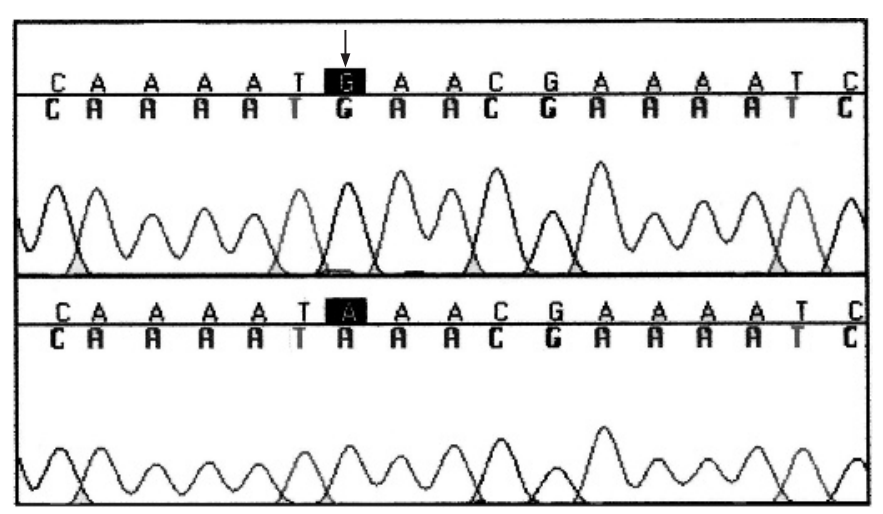

Figure 3 Molecular genetic analysis of the cybrid clones containing patient-derived mtDNA shows the mitochondrial nonsense mutation $\mathrm{m} .8529 \mathrm{G} \rightarrow \mathrm{A}$ (arrow). Top row: control cybrid cell line; bottom row: patient cybrid clone. Sequence analysis showed that all the clones are homoplasmic for the mutation (data not shown). 
Table 3 Enzymatic analysis of the complex $\mathrm{V}$ (mtATPase) activity in cybrids

\begin{tabular}{lll}
\hline Cybrid clone & $\begin{array}{l}\text { Complex V/COX } \\
\text { (mU/U COX) }\end{array}$ & $\begin{array}{l}\text { Complex V/CS } \\
\text { (mU/U CS) }\end{array}$ \\
\hline Control clone mixture & 2.0 & 0.3 \\
Patient clone 1 & 0.45 & 0.09 \\
Patient clone 2 & 0.08 & 0.02 \\
Patient clone 3 & 0 & 0 \\
Patient clone 4 & 0.56 & 0.09 \\
Patient clone 5 & 0 & 0 \\
Patient clone 6 & 0.87 & 0.07 \\
Patient clone 7 & 0.23 & 0.07
\end{tabular}

COX, cytochrome oxidase; CS, citrate synthase.

mitochondrial (neuropathy, ataxia) and nuclear (hypertrophic cardiomyopathy) complex V defects. Hypertrophic cardiomyopathy can present with negligible to extreme hypertrophy, minimal to extensive fibrosis and myocyte disarray, absent to severe left ventricular outflow tract obstruction, and distinct septal contours/morphologies with extremely varying clinical course. $^{23}$ The apical variant hypertrophic cardiomyopathy reported here represents a genotype-phenotype relationship that has not been described previously. Taken together, these data indicate that the clinical variability among the patient group carrying mitochondrial complex $\mathrm{V}$ mutations is greater than previously assumed.

\section{Pathogenicity}

Our results strongly suggest that the MT-ATP8 mutation is the cause of the complex $V$ deficiency in our patient. Several lines of evidence point to this: (1) the mutation leads to a premature stopcodon situated in the C-teminal region of subunit 8; (2) the C-terminal domain of mitochondrial ATP synthase subunit 8 is a conserved region in yeast ${ }^{21}$ and mammals ${ }^{10}$ (fig 2); (3) no polymorphisms have been described previously at the position of this mutation; $;^{10} 24$ (4) the mutation is homoplasmic (>90\%) in muscle tissue and fibroblasts, and in both tissues the complex $\mathrm{V}$ activity is clearly reduced (table 1); and (5) transmitochondrial cybrids retained the complex $\mathrm{V}$ deficiency, confirming the mitochondrial origin of the pathogenic mutation.

\section{Molecular pathophysiology}

Immunoblotting after BN-PAGE showed a lack of holocomplex $\mathrm{V}$ and increased amounts of subcomplexes, and the in-gel activity assay found isolated activity of $\mathrm{F}_{1}$-ATPase in the cybrids and in muscle. The results of the in-gel activity assay of ATP

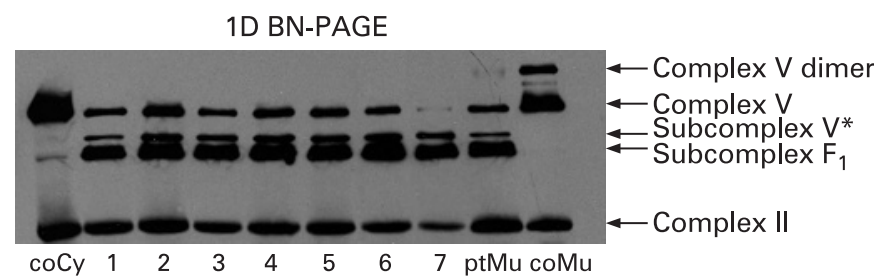

Figure 4 Immunoblotting after blue native polyacrylamide gel electrophoresis shows increased amounts of subcomplexes of mitochondrial ATP synthase in the patient cybrid clones and muscle. The control cybrid and muscle show only the complex $\mathrm{V}$ holoenzyme and dimer. Antibodies used are against ATP synthase subunit alpha and Coll$70 \mathrm{kDa}$ (complex II, loading control). Lane 1, control cybrid cell line (coCy); lanes 2-8, patient cybrid clones (1-7); lane 9, patient muscle homogenate (ptMu); lane 10, control muscle homogenate (coMu).

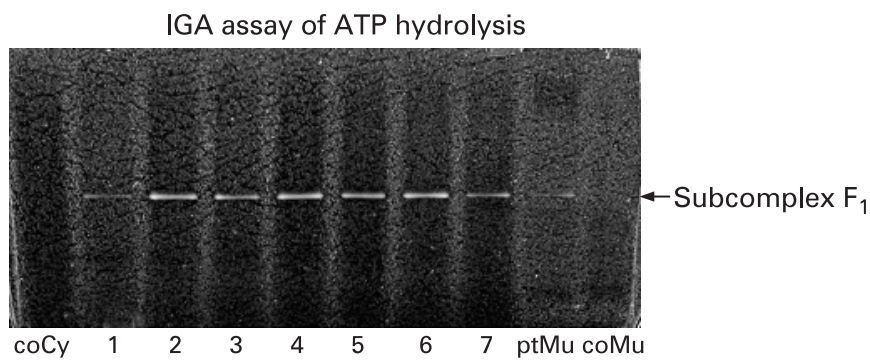

Figure 5 The in-gel activity (IGA) assay of ATP hydrolysis shows activity of free $F_{1}$-ATPase in the patient cybrid clones and muscle. Lane 1, control cybrid cell line (coCy); lanes 2-8, patient cybrid clones (1-7); lane 9, patient muscle homogenate (ptMu); lane 10, control muscle homogenate (coMu).

hydrolysis probably point to the free rotation capacity of the $\mathrm{F}_{1}$ subcomplex in the patient. It was reported that $\mathrm{F}_{1}$ can be detected as a single entity ${ }^{2}$ and that it retains ATP hydrolysis activity. ${ }^{22}$ The higher in-gel ATP hydrolysis activity of $\mathrm{F}_{1}$ ATPase has been described previously. ${ }^{22}$ It has been suggested that subunits of the $\mathrm{F}_{0}$ portion of ATP synthase restrict in-gel ATP hydrolysis, ${ }^{22}$ which results in an apparently low activity of the holocomplex in this assay. Whereas the in-gel activity assay showed an isolated $\mathrm{F}_{1}$-ATPase activity, the spectrophotometric assay demonstrated a very low $\mathrm{F}_{0} \mathrm{~F}_{1}$-ATPase activity.

The enzymatic assay measures the oligomycin-sensitive activity of complex $\mathrm{V} .{ }^{8}$ This is the result of the subtraction of the mtATPase holoenzyme activity and the activity after addition of oligomycin, an inhibitor of proton translocation in mtATPase. ${ }^{25}$ Athough the ATPase activity in the absence of oligomycin was of the same order of magnitude in our patient as in controls, the activity in the patient was not sensitive to oligomycin inhibition, whereas in control cells, usually a $90 \%$ inhibition is seen. In fact, detachment of the $\mathrm{F}_{1}$ from the $\mathrm{F}_{0}$ subcomplex, as seen on the $\mathrm{BN}$ gel data of the patient cybrid clones and muscle homogenate, leads to a decrease in oligomycin-sensitive complex V activity. ATP hydrolysis by $\mathrm{F}_{1}$ takes place, but without the coupling of ATP hydrolysis to extrusion of protons through $\mathrm{F}_{0}$, the sensitivity to oligomycin is no longer evident. ${ }^{25}$

How can the increased amounts of subcomplexes of complex $\mathrm{V}$ be explained? It has been reported that subunit 8 , which is unique to the mtATPase of fungi and mammals, consists of three functional domains: the $\mathrm{N}$-terminus, a central transmembrane hydrophobic domain and the C-terminus localised to the mitochondrial matrix side. ${ }^{26}{ }^{27}$ In yeast, the positively charged C-terminal region has been shown to be required for assembly of yeast subunit 8 (Y8) into the $\mathrm{F}_{0}$ sector. ${ }^{28}$ As $\mathrm{Y} 8$ interacts with other subunits in the assembly of the $\mathrm{F}_{0}$ sector, subunit 6 assembly into mtATPase requires the presence of assembled Y8 in the enzyme complex, ${ }^{29}$ thus it could be speculated that mutations in the C-terminal region, as present in our patient (the p.Trp55X, subunit 8 having 68 residues) are associated with reduced complex $\mathrm{V}$ assembly, which appears to be similar to the effect of human MT-ATP6 mutations. ${ }^{22}$ Our immunoblotting results confirm this hypothesis.

The impaired complex $\mathrm{V}$ assembly very likely has a repercussion on the function of the holoenzyme, as was shown in our patient by enzymatic analysis. Impaired subunit 6 assembly into the $\mathrm{F}_{0}$ sector possibly plays a role. It has been reported that subunit 6 has two functions: first, it leads the protons through a hydrophilic half-channel into the matrix, and second, it turns the rotor for ATP synthesis. ${ }^{30}$ The MT-ATP6 
$\mathrm{m} .8993 \mathrm{~T} \rightarrow \mathrm{G}$ mutation interferes with the rotation of the ring of c subunits, and therefore it uncouples ADP phosphorylation in $\mathrm{F}_{1}$ from proton transfer through $\mathrm{F}_{0}{ }^{30}$ The assembly problem is probably not the sole pathogenic factor. It is also likely that the subunit 8 protein is reduced due to the nature of the mutation in our patient, namely a premature stop codon, probably resulting in a truncated protein. In that case, a direct negative effect on the function of the enzyme could be assumed. It has indeed been described in yeast that $\mathrm{Y} 8$ also plays an important role in determining the mtATPase activity. ${ }^{26}$ In particular, the hydrophobic nature of amino acids in the centre of the transmembrane domain of $\mathrm{Y} 8$ is essential for coupling proton transport through $\mathrm{F}_{0}$ to ATP synthesis on $\mathrm{F}_{1} \cdot{ }^{26}$ Thus, $\mathrm{Y} 8$ may take part in conformational changes that occur between the $\mathrm{F}_{0}$ and $\mathrm{F}_{1}$ sectors of the enzyme during catalysis. ${ }^{26}$ However, further investigation is needed to confirm this.

Acknowledgements: AlJ and JS are supported by a grant from the Prinses Beatrix Fonds.

Competing interests: None.

\section{REFERENCES}

1. Sperl W, Jesina P, Zeman J, Mayr JA, De Meirleir L, Van Coster R, Pickova A Hansikova H, Houst'kova H, Krejcik Z, Koch J, Smet J, Muss W, Holme E, Houstek J. Deficiency of mitochondrial ATP synthase of nuclear genetic origin. Neuromuscul Disord 2006;16:821-9.

2. Nijtmans LG, Klement P, Houstek J, van den Bogert C. Assembly of mitochondrial ATP synthase in cultured human cells: implications for mitochondrial diseases. Biochim Biophys Acta 1995;1272:190-8.

3. Capaldi RA, Aggler R, Turina P, Wilkens S. Coupling between catalytic sites and the proton channel in $F_{1} F_{0}$ type ATPases. Trends Biochem Sci 1994;19:284-9.

4. Boyer PD. The ATP synthase - a splendid molecular machine. Annu Rev Biochem 1997;66:717-49.

5. Noji H, Yasuda R, Yoshida M, Kinosita K Jr. Direct observation of the rotation of $F_{1}$ ATPase. Nature 1997;386:299-302.

6. Nishio K, Iwamoto-Kihara A, Yamamoto A, Wada Y, Futai M. Subunit rotation of ATP synthase embedded in membranes: a or beta subunit rotation relative to the $\mathrm{c}$ subunit ring. Proc Natl Acad Sci USA 2002;99:13448-52.

7. Anderson S, Bankier AT, Barrell BG, De Bruijn MHL, Coulson AR, Drouin J, Eperon IC, Nierlich DP, Roe BA, Sanger F, Schreier PH, Smith AJH, Staden R, Young IG. Sequence and organisation of the human mitochondrial genome. Nature 1981;290:457-65.

8. Morava E, Rodenburg RJ, Hol F, de Vries M, Janssen A, van den Heuvel L, Nijtmans L, Smeitink J. Clinical and biochemical characteristics in patients with a high mutant load of themitochondrial T8993G/C mutations. Am J Med Genet A 2006;140:863-8.

9. De Meirleir L, Seneca S, Lissens W, De Clercq I, Eyskens F, Gerlo E, Smet J, Van Coster R, Respiratory chain complex $V$ deficiency due to a mutation in the assembly gene ATP12. J Med Genet 2004;41:120-4.
10. MITOMAP. A human mitochondrial genome database. http://www.mitomap.org, 2006.

11. King MP, Attadi G. Mitochondria-mediated transformation of human rho(0) cells. Methods Enzymol 1996:264:313-34.

12. Janssen AJM, Trijbels FJM, Sengers RCA, Wintjes LTM, Ruitenbeek W, Smeitink JAM, Morava E, van Engelen BGM, van den Heuvel LP, Rodenburg RJT. Measurement of the energy-generating capacity of human muscle mitochondria: diagnostic procedure and application to human pathology. Clin Chem 2006;52:86071.

13. Cooperstein SJ, Lazarow A. A microspectrophotometric method for the determination of cytochrome oxidase. J Biol Chem 1951;189:665-70.

14. Srere PA. Citrate synthase. Methods Enzymol 1969;13:3-11.

15. Smeitink J, Sengers R, Trijbels F, van den Heuvel L. Human NADH:ubiquinone oxidoreductase. J Bioenerg Biomembr 2001;33:259-66.

16. Janssen AJ, Smeitink JA, van den Heuvel LP. Some practical aspects of providing a diagnostic service for respiratory chain defects. Ann Clin Biochem 2003;40:3-8.

17. Lowik MM, Hol FA, Steenbergen EJ, Wetzels JF, van den Heuvel LP. Mitochondrial tRNA ${ }^{\text {Leu(UUR) }}$ mutation in a patient with steroid-resistant nephrotic syndrome and focal segmental glomerulosclerosis. Nephrol Dial Transplant 2005;20:336-41.

18. Schägger $\mathbf{H}$, von Jagow G. Blue native electrophoresis for isolation of membrane protein complexes in enzymatically active form. Anal Biochem 1991;199:223-31.

19. Nijtmans LG, Henderson NS, Holt IJ. Blue native electrophoresis to study mitochondrial and other protein complexes. Methods 2002;26:327-34.

20. Smith PK, Krohn RI, Hermanson GT, Mallia AK, Gartner FH, Provenzano MD, Fujimoto EK, Goeke NM, Olson BJ, Klenk DC. Measurement of protein using bicinchoninic acid. Anal Biochem 1985;150:76-85

21. Straffon AF, Nagley P, Devenish RJ. Rescue of yeast defective in mitochondrial ATP synthase subunit 8 by a heterologous gene from Aspergillus nidulans. Biochem Biophys Res Commun 1994;203:1567-73.

22. Nijtmans LG, Henderson NS, Attardi G, and Holt IJ. Impaired ATP synthase assembly associated with a mutation in the human ATP synthase subunit 6 gene. J Biol Chem 2001;276:6755-62.

23. Bos JM, Ommen SR, Ackerman MJ. Genetics of hypertrophic cardiomyopathy: one, two, or more diseases? Curr Opin Cardiol 2007:22:193-9.

24. Ingman M, Gyllensten U. mtDB: Human Mitochondrial Genome Database, a resource for population genetics and medical sciences. Nucleic Acids Res 2006;34:D749-51.

25. Devenish RJ, Prescott M, Boyle GM, Nagley P. The oligomycin axis of mitochondrial ATP synthase: OSCP and the proton channel. J Bioenerg Biomembr 2000;32:507-15.

26. Devenish RJ, Prescott M, Roucou X, Nagley P. Insights into ATP synthase assembly and function through the molecular genetic manipulation of subunits of the yeast mitochondrial enzyme complex. Bioch Biophys Acta 2000;1458:428-42.

27. Belogrudov GI, Tomich JM, Hatefi Y. Membrane topography and near-neighbor relationships of the mitochondrial ATP synthase subunits e, f and g. J Biol Chem 1996;271:20340-45.

28. Papakonstantinou T, Galanis M, Nagley P, Devenish RJ. Each of the three positively-charged amino-acids in the C-terminal region of yeast mitochondrial ATP synthase subunit 8 is required for assembly. Biochim Biophys Acta 1993;1144:22-32.

29. Hadikusumo RG, Meltzer S, Choo WM, Jean-Francois MJ, Linnane AW, Marzuki S. The definition of mitochondrial $\mathrm{H}^{+} \mathrm{ATP}$ ase assembly defects in mit- mutants of Saccharomyces cerevisiae with a monoclonal antibody to the enzyme complex as an assembly probe. Biochim Biophys Acta 1988;933:212-22.

30. Sgarbi G, Baracca A, Lenaz G, Valentino LM, Carelli V, Solaini G. Inefficient coupling between proton transport and ATP synthesis may be the pathogenic mechanism for NARP and Leigh syndrome resulting from the T8993G mutation in mtDNA. Biochem J 2006;395:493-500. 